\title{
Mikron Altı Boyutlu Alümina Katkısının ve Soğuk Deformasyon İșleminin Üretilen Alüminyum Kompozit Yapının Mekanik Özellikleri ve Mikroyapısına Etkisi
}

\author{
Effect of Submicron-Sized Alumina Addition and Cold Working Process on Mechanical \\ Properties and Microstructure of Aluminum Based Composite Structure
}

\author{
Mahmut Can ŞENEL ${ }^{* a}$, Mevlüt GÜRBÜZ ${ }^{b}$ \\ Ondokuz Mayıs Üniversitesi, Mühendislik Fakültesi, Makina Mühendisliği Bölümü, 55210, Samsun
}

• Geliş tarihi / Received: 18.02.2019 •Düzeltilerek geliş tarihi / Received in revised form: 17.09.2019 • Kabul tarihi / Accepted: 11.10.2019

$\ddot{O ̈ z}$

$\mathrm{Bu}$ çalışma kapsamında, toz metalurjisi yöntemiyle ağırlıkça farklı alümina $\left(\mathrm{Al}_{2} \mathrm{O}_{3}\right)$ katkı oranlarında (ağılıkça $\% 0,0.5$, $1,1.5,2,2.5)$ mikron altı boyutlu alümina takviyeli alüminyum matrisli kompozitler üretilmiştir. Üretilen kompozit malzemelere uygulanan mekanik testler sonucunda, en iyi mekanik özellikler $\mathrm{Al}-\% 2 \mathrm{Al}_{2} \mathrm{O}_{3}$ kompozit yapıda ulaşılmıştır. Üretilen $\mathrm{Al}-\% 2 \mathrm{Al}_{2} \mathrm{O}_{3}$ kompozitlerin mekanik özelliklerini artırmak amacıyla farklı soğuk şekil değişim oranlarında soğuk işlem uygulanmıştır. Soğuk işlemin $\mathrm{Al}-\% 2 \mathrm{Al}_{2} \mathrm{O}_{3}$ kompozitlerin gözenekliliğine, yoğunluğuna, sertliğine, çekme dayanımına ve mikroyapısına olan etkisi incelenmiştir. Malzemelerin kristal yapısı ve mikroyapısı sırasıyla, X-1̧̧ını kırınımı (XRD) cihazı ve taramalı elektron mikroskobuyla (SEM) analiz edilmiş̧tir. Test sonuçlarına göre; \%11.8 soğuk şekil değişim oranına kadar $\mathrm{Al}-\% 2 \mathrm{Al}_{2} \mathrm{O}_{3}$ kompozitin mekanik özelliklerinin iyileştiği tespit edilmiştir. $\mathrm{Al}-\% 2 \mathrm{Al}_{2} \mathrm{O}_{3}$ kompozit yapıda \%11.8 soğuk şekil değişimi için, Vickers sertliğinin 43HV'den 68 HV'ye (\%53 oranında), çekme dayanımının ise $71 \mathrm{MPa}$ 'dan $92 \mathrm{MPa}$ 'a kadar arttı̆̆ı (\%30 oranında) tespit edilmiştir.

Anahtar kelimeler: Alüminyum, Alümina, Mekanik Özellik, Soğuk İşlem, Toz Metalurjisi

\begin{abstract}
In this study, submicron-sized alumina reinforced aluminum matrix composites with various alumina $\left(\mathrm{Al}_{2} \mathrm{O}_{3}\right)$ content $(0$, $0.5,1,1.5,2,2.5 w t . \%)$ were fabricated by the powder metallurgy method. As a result of the mechanical tests performed to the composite materials, the best mechanical properties were obtained at the Al-2\% $\mathrm{Al}_{2} \mathrm{O}_{3}$ composite structure. Cold working at the different cold work strain ratios was performed to increase the mechanical properties of $\mathrm{Al}_{-} 2 \% \mathrm{Al}_{2} \mathrm{O}_{3}$ composites. The effect of cold working on the porosity, apparent density, tensile strength, and Vickers hardness of Al$2 \% \mathrm{Al}_{2} \mathrm{O}_{3}$ composites was investigated. The microstructure and crystal structure of materials were analyzed with $\mathrm{X}$-ray diffraction (XRD) device and scanning electron microscopy (SEM), respectively. According to the test results, the mechanical properties of $\mathrm{Al}-2 \% \mathrm{Al}_{2} \mathrm{O}_{3}$ composite were enhanced up to $11.8 . \%$ cold working rate. It was determined that the Vickers hardness increased from $43 \mathrm{HV}$ to $68 \mathrm{HV}(+53 \%)$ and the compressive strength improved from $71 \mathrm{MPa}$ to $92 \mathrm{MPa}(+30 \%)$ for $11.8 \%$ cold working rate in $\mathrm{Al}-2 \% \mathrm{Al}_{2} \mathrm{O}_{3}$ composite structure.
\end{abstract}

Keywords: Aluminum, Alumina, Mechanical Property, Cold Working, Powder Metallurgy

\footnotetext{
*a Mahmut Can ŞENEL; mahmutcan.senel@omu.edu.tr, Tel: (0362) 312 19 19/1315, orcid.org/0000-0001-7897-1366

${ }^{\mathrm{b}}$ orcid.org/0000-0003-2365-5918
} 


\section{Giriş}

Kompozit malzemeler, iki veya daha fazla malzemenin üstün özelliklerini tek bir malzemede toplamak amaciyla geliştirilen yeni bir malzeme grubudur. Kompozit malzemeler; metal, seramik ve polimer matrisli kompozitler şeklinde sinıflandırılmaktadır (Şenel vd. 2015; Şahin, 2006). Metal matrisli kompozitlerde, matris malzeme olarak metal (alüminyum, magnezyum, titanyum, bakır vb.) veya metal alaşımı kullanılmaktadır. Takviye elemanı olarak da genellikle metal oksit $\left(\mathrm{ZrO}_{2}, \mathrm{Al}_{2} \mathrm{O}_{3}, \mathrm{SiO}_{2}\right.$ vb.), metal nitrür $\left(\mathrm{BN}, \mathrm{Si}_{3} \mathrm{~N}_{4}, \mathrm{TiN}\right.$, vb.) ve metal karbür (WC, $\mathrm{SiC}, \quad \mathrm{B}_{4} \mathrm{C}, \quad$ vb.) gibi seramik esaslı malzemeler kullanılmaktadır (Öztop ve Gürbüz, 2018).

Matris malzeme olarak kullanılan alüminyumun (Al), sahip olduğu üstün özellikler (kolay işlenebilirlik, hafiflik ve iyi elektriksel iletkenlik vb.) sayesinde günümüzde havacilık, otomotiv, uzay ve elektronik sektörlerinde yaygın olarak kullanılmaktadır (Martinez vd., 2017). Alüminyum birtakım önemli fiziksel ve kimyasal özelliklere sahip bir element olup alüminyumun atom ağırlığ1 $26.98 \mathrm{~g} / \mathrm{mol}$ ve atom numaras1 13 'dür. Alüminyum oda sıcaklı̆̆ında $2.7 \mathrm{~g} / \mathrm{cm}^{3}$ yoğunluğa sahip olup alüminyumun isıl iletkenliği $237 \mathrm{~W} /\left(\mathrm{m}^{\circ} \mathrm{K}\right)$, sertliği $30 \mathrm{HV}$ ve ergime sicaklığ 1 $660{ }^{\circ} \mathrm{C}$ 'dir (Şenel vd., 2017).

Takviye elemanı olarak kullanılan alüminanın $\left(\mathrm{Al}_{2} \mathrm{O}_{3}\right)$ sahip olduğu yüksek sertlik, yüksek basma dayanımı ve refrakterlik özelliği sebebiyle kesici takımlarda, pompa parçalarında, motor parçalarında, türbin yataklarında, sızdırmazlık elemanlarında ve bujilerde siklıkla kullanılmaktadır. Alüminanın teorik yoğunluğu $3.98 \mathrm{~g} / \mathrm{cm}^{3}$, sertliği $200 \mathrm{HV}$ ve ergime sicaklığ $2050{ }^{\circ} \mathrm{C}$ 'dir (Srivastava ve Chaudhari, 2018; Kok, 2005).

Metal matrisli kompozitler; çoğunlukla toz metalurjisi, sicak haddeleme veya sıkıştırma döküm yöntemiyle üretilmektedir. Diğer üretim yöntemleri arasında toz metalurjisi yöntemi, son şekle yakın, homojen, gözenekli ve karmaşık parça üretimi gibi avantajlara sahiptir. $\mathrm{Bu}$ sebeple, bu çalışmada toz metalurjisi yöntemiyle $\mathrm{Al}-\mathrm{Al}_{2} \mathrm{O}_{3}$ kompozitlerin üretimi amaçlanmıştır (Torralba vd., 2003; Kaczmar vd., 2000).

Alüminyumun (Al) mekanik özelliklerinin arttır1lmasi; $\mathrm{Al}_{2} \mathrm{O}_{3}, \mathrm{~B}_{4} \mathrm{C}, \mathrm{SiC}, \mathrm{Si}_{3} \mathrm{~N}_{4}$ gibi seramik malzeme katkısıyla, sıcak/soğuk işlemle veya mekanik alaşımlama yöntemi gibi proseslerle gerçekleştirilmektedir (Sharma vd., 2015; Bastwros vd., 2014; Lianggang vd., 2015; Burlat vd., 2015). Bu işlemler sonucunda; sertlik, çekmeakma dayanımı ve tokluk gibi mekanik özellikler artmaktadır. Soğuk işlem, mekanik özellikleri iyileştirme işlemlerinden biridir. Soğuk işlem; deformasyon sertleşmesi, pekleşme ve soğuk şekillendirme şeklinde de ifade edilebilmektedir. Metallerin büyük çoğunluğunun mekanik dayanımı, oda sıcaklığında gerçekleşen deformasyonun etkisiyle artmaktadır. Soğuk şekil değişimi sonrasında oluşan plastik deformasyon seviyesini belirlemek amacıyla yüzde soğuk şekil değişimi (\%SŞD) ifadesi kullanılmaktadır (Ashtiani ve Karami, 2015; Callister ve Rethwicsch, 2014).

Literatürdeki çalışmalar incelendiğinde; alümina katk1lı alüminyum matrisli kompozitlerin mikroyapısı ve mekanik özelliklerinin araştırılması üzerine çeşitli çalışmalar mevcuttur (Srivasta ve Chaudhari, 2018; Kok, 2005; Ezatpour vd., 2016; Sajjadi vd., 2011; Rahimian vd., 2011). Yürütülen bir çalışmada (Srivasta ve Chaudhari, 2018), ağırlıkça \%1, 2, 3 nano alümina takviyeli Al6061 kompozitlerin mekanik özellikleri ve mikroyapısı incelenmiştir. En iyi mekanik özellikler Al6061-\%2 $\mathrm{Al}_{2} \mathrm{O}_{3}$ kompozit yapıda elde edilmiş olup akma dayanımı $+\% 81$ ve Vickers sertliği $+\% 76$ oranında iyileşmiştir. Ağırlıkça \%2 nano $\mathrm{Al}_{2} \mathrm{O}_{3}$ katkısından sonra mikro çatlakların oluşumu sebebiyle mekanik özelliklerin kötüleştiği tespit edilmiştir. Bir diğer çalışmada (Ezatpour vd., 2016), ağırlıkça \%0.4, 0.8, 1.2 katk11 nano alümina katk1lı Al7075 matrisli kompozitlerin mikroyapısı ve mekanik özellikleri araştırılmıştır. En iyi mekanik özellikler, $\% 0.4 \mathrm{Al}_{2} \mathrm{O}_{3}$ katkılı alüminyum matrisli kompozit yapıda elde edilmiştir. $\mathrm{Bu}$ katkı oranından sonra, nano alümina taneciklerin topaklanması sebebiyle üretilen kompozitlerin mekanik özelliklerinin kötüleştiği tespit edilmiştir. Literatürdeki çalışmalar incelendiğinde; mikron alt1 boyutlu alümina $\left(\mathrm{Al}_{2} \mathrm{O}_{3}\right)$ katk1 oranının ve \%soğuk şekil değişiminin $\mathrm{Al}-\mathrm{Al}_{2} \mathrm{O}_{3}$ kompozitlerin mekanik özelliklerine ve mikroyapısına olan etkisinin incelenmesine yönelik herhangi bir çalışmaya rastlanmamıştır.

$\mathrm{Bu}$ çalışmada, ağırlıkça farklı katkı oranlarında (ağırlıkça \%0, 0.5, 1, 1.5, 2, 2.5) mikron altı boyutlu alümina takviyeli alüminyum matrisli kompozitler toz metalurjisi yöntemiyle üretilmiştir. Yürütülen test çalışmalarında, en yüksek Vickers sertliğine ve deneysel yoğunluğa sahip en uygun alümina katkı oranı belirlenmiştir. $\mathrm{Bu}$ katk1 oranı ve kompozit yapı esas alınarak 
\%soğuk şekil değişiminin (\%SŞD) kompozitin deneysel yoğunluğuna, Vickers sertliğine, çekme dayanımına ve mikroyapısına olan etkisi analiz edilmiştir.

\section{Materyal ve Yöntem}

\subsection{Materyal}

$\mathrm{Bu}$ çalışmada, $\mathrm{Al}-\mathrm{Al}_{2} \mathrm{O}_{3}$ kompozit malzeme üretiminde ana malzeme olarak $\mathrm{Al}$ tozu, takviye elemanı olarak ise mikron altı boyutlu $\mathrm{Al}_{2} \mathrm{O}_{3}$ tozu kullanılmıştır. Alüminyum tozu Alfa Aeasar firmasindan, alümina tozu ise Panadyne Inc. firmasından temin edilmiştir. Ticari olarak temin edilen alüminyum ve alümina tozlarının genel özellikleri Tablo 1'de verilmiştir (Şahin, 2014; Kurşun, 2011).

Tablo 1. Alüminyum ve alümina tozlarının genel özellikleri (Şahin, 2014; Kurşun, 2011).

\begin{tabular}{c|ccc}
\hline Malzeme & $\begin{array}{c}\text { Saflık } \\
\text { Derecesi } \\
(\boldsymbol{\%})\end{array}$ & $\begin{array}{c}\text { Tanecik } \\
\text { boyut } \\
\text { aralığı } \\
(\boldsymbol{\mu m})\end{array}$ & $\begin{array}{c}\text { Teorik } \\
\mathbf{y o g ̆ u n l u g ̆ \mathbf { ~ }} \\
\left(\mathbf{g} / \mathbf{c m}^{\mathbf{3}}\right)\end{array}$ \\
\hline Alüminyum & 99 & $8-15$ & 2.7 \\
$\mathrm{Al}_{2} \mathrm{O}_{3}$ & 98 & $0.3-0.6$ & 3.97 \\
\hline
\end{tabular}

\subsection{Yöntem}

$\mathrm{Bu}$ çalışmada, toz metalurjisi yöntemiyle mikron altı boyutlu alümina katkılı alüminyum matrisli kompozitler üretilmiştir (Şekil 1). Öncelikle, alümina tozu etanol içerisinde ultrasonik dağıtıcıyla dağıtılır. Aynı süreçte, saf $\mathrm{Al}$ tozu etanol içerisinde mekanik karıştırıcıyla karıştırılır. Daha sonra, alüminyum çözeltisi azar azar alümina çözeltisine eklenerek karıştırılır. Karıştırma sonrası, karışımdan etanolü uzaklaştırmak için karışım filtrelenir ve $45^{\circ} \mathrm{C}$ sicaklıkta vakum altında bir gece boyunca kurutulur. Kurutulan karışım, tek eksenli presle 600 MPa'lık bir basınçta sıkıştırılır. Şekillendirilen numuneler $630{ }^{\circ} \mathrm{C}$ sicaklıkta ve 3 saat süresince sinterlenir. Soğuk şekil değişiminin kompozitin mekanik özelliklerine olan etkisini incelemek amaciyla kompozitler farklı basma gerilmeleri (50-100-150-200-250 MPa) altında preslenerek farklı \%soğuk şekil değişimleri (\%SŞD) elde edilmiştir. SŞD öncesi ve sonrası kompozit malzemelerin gözeneklilik oranı, deneysel yoğunluğu ve Vickers sertliği ölçülmüştür. Kompozitlerin yoğunluğu ve gözeneklilik oranı Arşimet yoğunluk ölçüm cihazıyla, Vickers sertliği HV1000B mikro Vickers sertlik ölçüm cihazıyla tespit edilmiştir.
Vickers sertliği, $200 \mathrm{~g}$ yük altında ve numune yüzeyindeki en az beş (5) farklı noktadan ölçülen sertlik değerinin ortalaması alınarak belirlenmiştir. Kompozitlerin çekme dayanımı, üniversal test makinasiyla (Mares Test-10 ton) belirlenmiştir. Toz metalurjisi yöntemiyle üretilen kompozitlerin mikroyapıları optik mikroskopla (SOIF BK300T) ve taramalı elektron mikroskobuyla (SEM, Jeol JSM-7001F), kristal yapıları ise $\mathrm{X}-1$ şını kırınımı (XRD, Rigaku Smartlab) cihazıyla incelenmiştir (Gürbüz vd., 2018a; Şenel, 2018).

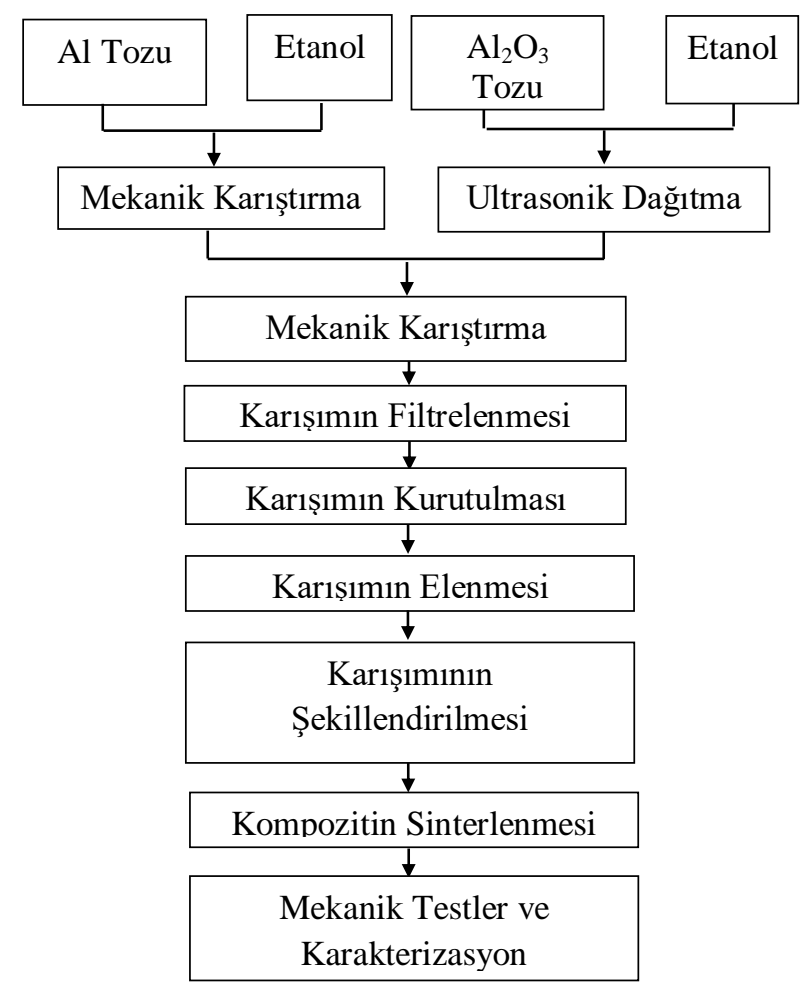

Şekil 1. Alümina katk1lı alüminyum matrisli kompozitlerin üretim şeması (Şenel, 2018).

\section{Bulgular ve Tartışma}

\subsection{Tozların Karakterizasyonu}

Tozların taramalı elektron mikroskobu (SEM) görüntüleri ve X-1şını kırınımı (XRD) faz analizleri Şekil 2'de verilmiştir. SEM görüntülerinden; alüminyum (Al) ve alümina $\left(\mathrm{Al}_{2} \mathrm{O}_{3}\right)$ tozlarının süngerimsi ve düzensiz bir morfolojide olduğu, ortalama $\mathrm{Al}$ ve $\mathrm{Al}_{2} \mathrm{O}_{3}$ tanecik boyutunun sirasiyla $10 \mu \mathrm{m}$ ve $0.5 \mu \mathrm{m}$ olduğu görülmüştür (Şekil $2 \mathrm{a}$ ve $2 \mathrm{~b}$ ). Alümina ve saf alüminyum tozlarına ait $\mathrm{X}$ - 1şını kırınım açılarının sirasiyla; $2 \theta=\sim 25^{\circ}, 35^{\circ}, 38^{\circ}, 43^{\circ}, 53^{\circ}, 58^{\circ}, 61^{\circ}$, $67^{\circ}, 68^{\circ}, 77^{\circ}$ ve $2 \theta=\sim 38^{\circ}, 45^{\circ}, 65^{\circ}, 78^{\circ}$ olduğu belirlenmiştir (Şekil 2c ve 2d). 

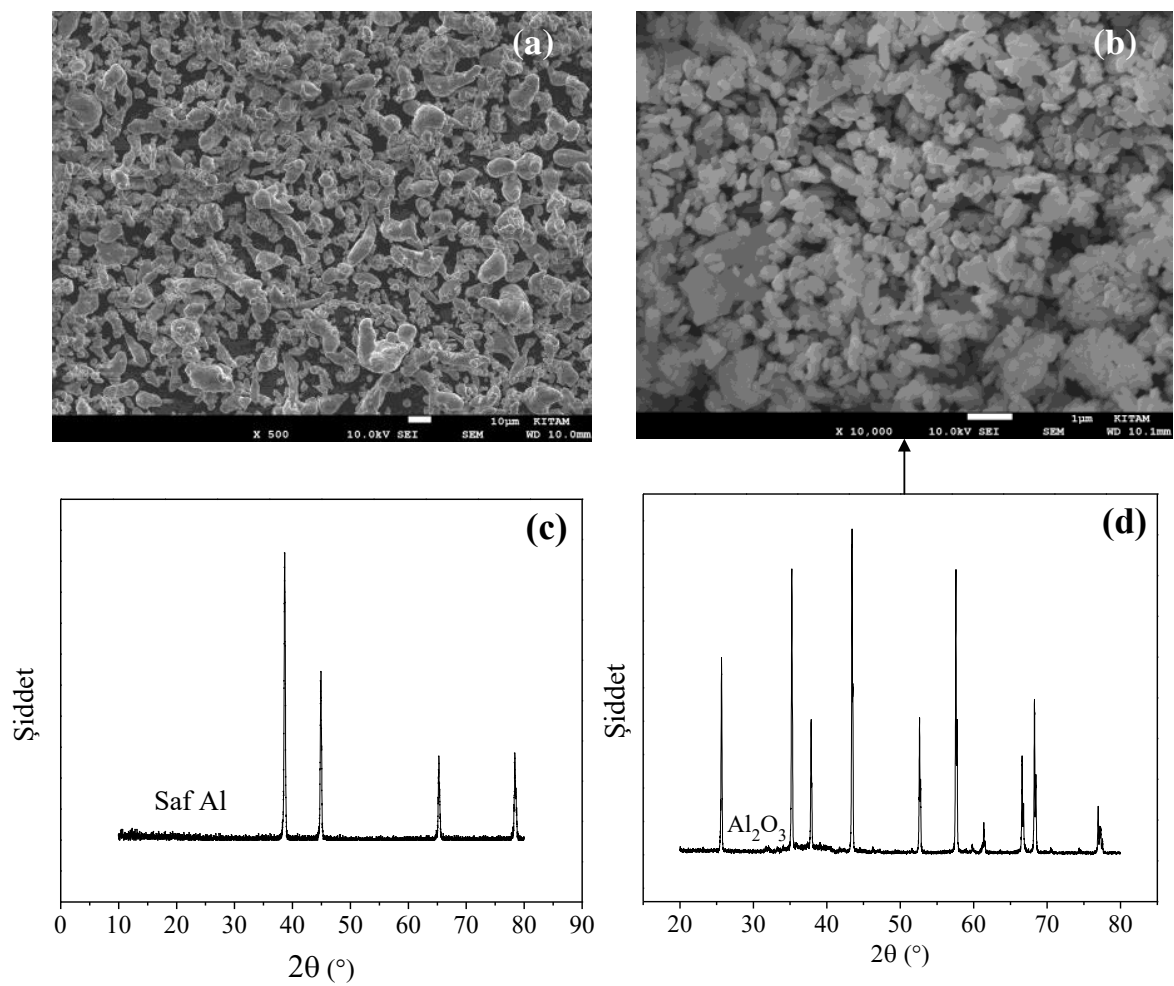

Şekil 2. Tozlara ait SEM görüntüleri ve XRD faz analizleri: (a, c) saf alüminyum ve (b, d) alümina.

\subsection{Soğuk Şekil Değişimi Öncesi Kompozitlerin Mekanik Özellikleri}

$\mathrm{Bu}$ bölümde, soğuk şekil değişimi öncesi $\mathrm{Al}$ $\mathrm{Al}_{2} \mathrm{O}_{3} \quad$ kompozitlerin mekanik özellikleri belirlenmiş̧ir. Kompozitlerin deneysel yoğunluğu ( $\rho)$ ve \%gözeneklilik oranı $(\% \mathrm{P})$ Arşimet yöntemiyle tespit edilmiş olup Eşitlik (1) ve (2)'de verilmiştir (German, 2007).

$\rho=\left[\left(m_{K}\right) /\left(m_{D}-m_{A}\right)\right] \times \rho_{s u}$

$\% P=\left(m_{D}-m_{K}\right) /\left(m_{D}-m_{A}\right) \times 100$
Burada, $\rho_{\text {su }}$ suyun yoğunluğu $\left(1 \mathrm{~g} / \mathrm{cm}^{3}\right), m_{K}$ kompozitlerin kuru ağırlı̆̆ $1, m_{D}$ doymuş ağırlığ 1 ve $\mathrm{m}_{\mathrm{A}}$ ise askı a $\breve{g} ı r l ı \breve{g} 1 \mathrm{~d} ı r$.

Alümina katk1 oranıla $\mathrm{Al}-\mathrm{Al}_{2} \mathrm{O}_{3}$ kompozitlerin deneysel yoğunluğundaki ve gözeneklilik oranındaki değișim Șekil 3'de verilmiștir. En düşük gözeneklilik oranı $(\% 2.4)$ ve maksimum deneysel yoğunluk $\left(2.66 \mathrm{~g} / \mathrm{cm}^{3}\right) \quad \mathrm{Al}-\% 2 \mathrm{Al}_{2} \mathrm{O}_{3}$ kompozit yapıda elde edilmiştir. Ağırlıça \%2 alümina katkısından sonra alüminyum kompozitin deneysel yoğunluğu azalmış, gözeneklilik oranı artmıştır. Bu durumun, kompozit yapıdaki mikron alt1 boyutlu alümina taneciklerin topaklanmasından kaynaklandığı düşünülmektedir.

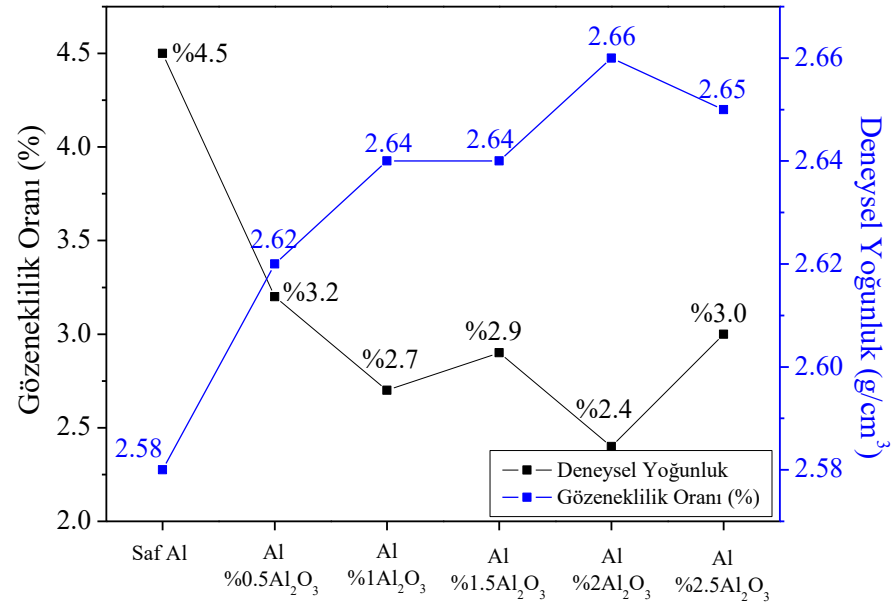

\Şekil 3. $\mathrm{Al}-\mathrm{Al}_{2} \mathrm{O}_{3}$ kompozit yapıda alümina katk1 oranıla deneysel yoğunluk ve gözeneklilik oranındaki değişim. 
Alümina katkı oranıla $\mathrm{Al}-\mathrm{Al}_{2} \mathrm{O}_{3}$ kompozitlerin Vickers sertliğindeki değişim Şekil 4'de verilmiştir. Saf alüminyumun Vickers sertliği $30 \pm 1.5 \mathrm{HV}$ iken; $\mathrm{Al}-\% 2 \mathrm{Al}_{2} \mathrm{O}_{3}$ kompozitinki $43 \pm 2$ HV'ye yükselmiştir. Ağırlıça \%2 alümina katkısından sonra alümina partiküllerin topaklanmas1 sebebiyle kompozitin Vickers sertliği düşmüsşür. $\mathrm{Bu}$ sebeple, $\mathrm{Al}-\% 2 \mathrm{Al}_{2} \mathrm{O}_{3}$ kompozit yapı esas alınarak farklı şekil değişimi oranlarında soğuk deformasyon işlemi uygulanmıştır.

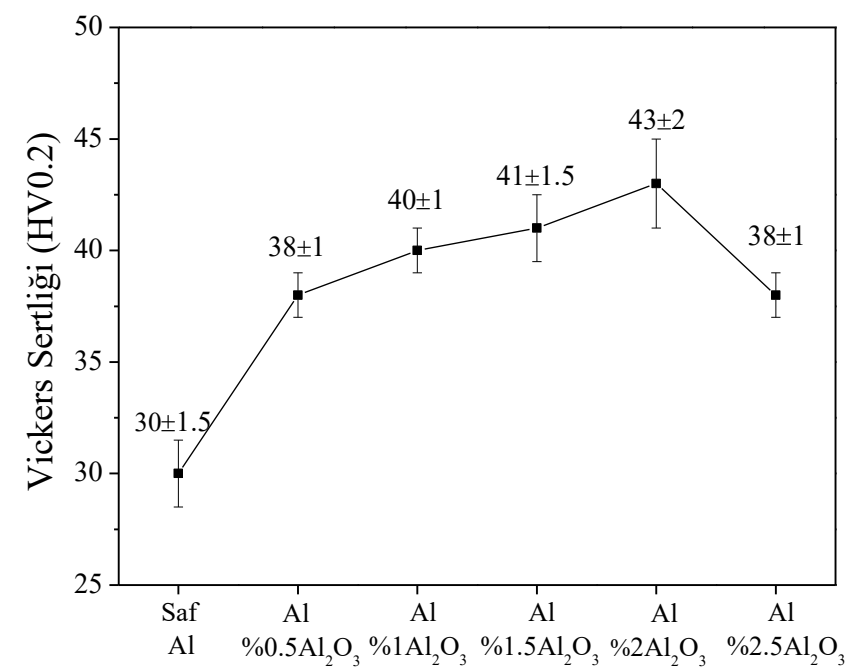

Şekil 4. $\mathrm{Al}-\mathrm{Al}_{2} \mathrm{O}_{3}$ kompozit yapıda alümina katkı oranıyla Vickers sertliğindeki değişim.

\subsection{Soğuk Şekil Değişimi Sonrası Kompozitlerin Mekanik Özellikleri}

Soğuk şekil değişiminin kompozitin mekanik özelliklerine olan etkisini tespit etmek amaciyla numuneler farklı basma gerilmelerine (0-250 MPa aras1) maruz bırakılmıştır. Yüzde soğuk şekil değişimi (\%SŞD) ifadesi, Eşitlik (3)'de verilmiştir (Callister ve Rethwicsch, 2014; Gürbüz, 2018b).

$\% \mathrm{SSSD}=\left[\left(\mathrm{A}_{0}-\mathrm{A}_{\mathrm{d}}\right) / \mathrm{A}_{0}\right] \times 100$

$\mathrm{Bu}$ eşitlikte, $\mathrm{A}_{\mathrm{d}}$ deformasyon sonrası kesit alanını ve $A_{0}$ ise deformasyon öncesi kesit alanını ifade etmektedir. Uygulanan basma gerilmelerine karşıllık yüzde şekil değişiminin (\%SŞD) \%1.9'dan \%23.5'e kadar arttı̆̆ belirlenmiştir (Tablo 2).

Tablo 2. Uygulanan basma gerilmesine karşıllk \%SŞD miktarı.

\begin{tabular}{c|c}
\hline Basma Gerilmesi (MPa) & SŞD (\%) \\
\hline 50 & 1.9 \\
100 & 6.1 \\
150 & 11.8 \\
200 & 13 \\
250 & 23.5 \\
\hline
\end{tabular}

Soğuk işlemin etkisiyle $\mathrm{Al}-\% 2 \mathrm{Al}_{2} \mathrm{O}_{3}$ kompozitlerin gözeneklilik oranı ve deneysel yoğunluğundaki değişim Şekil 5'de verilmiştir.
Şekilden \%11.8 SŞD’ye kadar kompozitin gözeneklilik oranının azaldığı, deneysel yoğunluğun ise arttı̆̆ı görülmüştür. $\mathrm{Bu}$ orandan sonra ise aşırı plastik deformasyon oluşumu sebebiyle yoğunluk değerinde düşüş, gözeneklilik oranında ise artış tespit edilmiştir. Soğuk deformasyon öncesi deneysel yoğunluk ve gözeneklilik oranı $2.66 \mathrm{~g} / \mathrm{cm}^{3}$ ve $\% 2.4$ iken; $\% 11.8$ SŞD oranında bu değerler $2.7 \mathrm{~g} / \mathrm{cm}^{3}$ ve $\% 1$ 'dir. Deneysel yoğunluktaki artışın, artan soğuk şekil değişimi etkisiyle içyapıdaki gözeneklerin kapanmasından kaynaklandığ1 düşünülmektedir (Gökmeşe ve Bostan, 2013).

Üretilen $\mathrm{Al}-\% 2 \mathrm{Al}_{2} \mathrm{O}_{3}$ kompozitlerin yüzde soğuk şekil değişimiyle Vickers sertliğindeki değişim Şekil 6'da verilmiştir. Soğuk işlem öncesi üretilen $\mathrm{Al}-\% 2 \mathrm{Al}_{2} \mathrm{O}_{3}$ kompozitin Vickers sertliği $43 \pm 2 \mathrm{HV}$ iken; \%11.8 soğuk şekil değişim oranında Vickers sertlik değeri $68 \pm 1.5$ HV'ye (+\%53 oranında) yükselmiştir. Daha fazla soğuk şekil değişiminde ise kompozit malzemenin yan yüzeylerinde şişme oluşmuş olup basma gerilmesinin artmasıyla malzeme yüzeyinde ve içyapida çatlaklar meydana gelmiştir. Bu çatlaklar ise gözenek gibi davrandiğından deneysel yoğunluğun ve Vickers sertliğinin düşmesine sebep olmuştur. $\mathrm{Bu}$ yüzden çekme testi, en yüksek Vickers sertlik değerinin elde edildiği \%11.8 SŞD'ye maruz kalan Al$\% 2 \mathrm{Al}_{2} \mathrm{O}_{3}$ kompozit yapıya uygulanmıştır. 


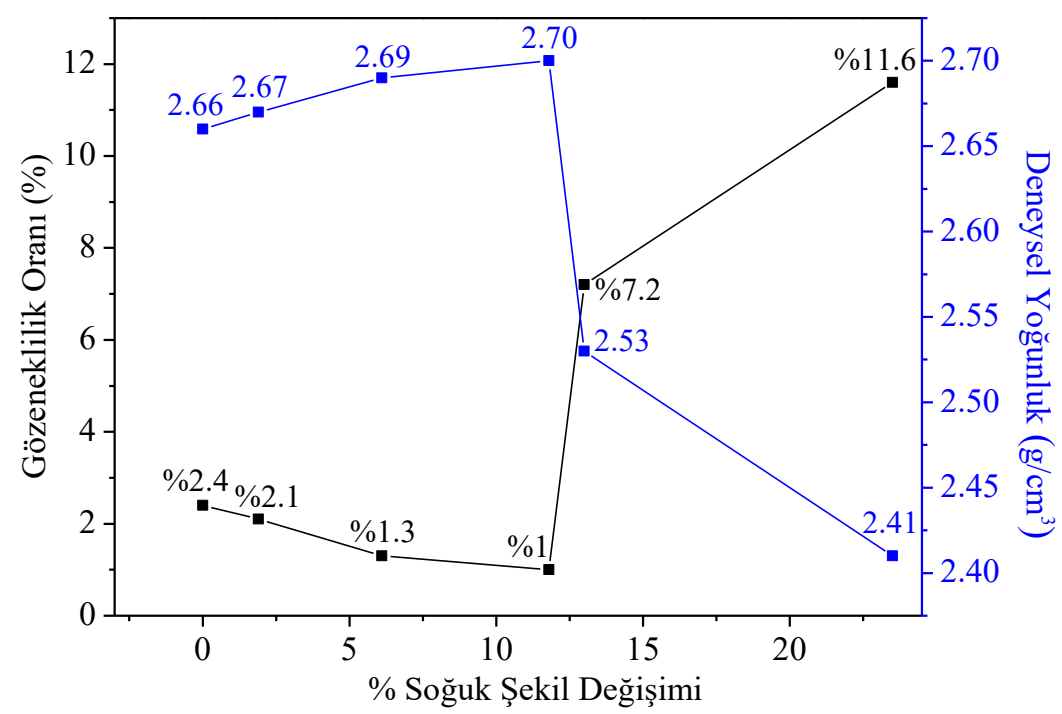

Şekil 5. Al-\% $2 \mathrm{Al}_{2} \mathrm{O}_{3}$ kompozit yapıda \%soğuk şekil değişimiyle (\%SŞD) deneysel yoğunluk ve gözeneklilik oranı değişimi.

Çok kristalli bir metal veya metal alaşımı, soğuk şekil değişimine uğradığında basma durumunda taneler basmaya dik yönde, çekme durumunda ise çekme yönünde uzama göstermektedir. Soğuk şekil değişimi sonrası oluşan pekleşme ve yoğunluk artışı sebebiyle kompozitin Vickers sertliği artmıştır (Çapan, 2003; Mansourinejad ve Mirzakhani, 2012; Hou vd., 2015).

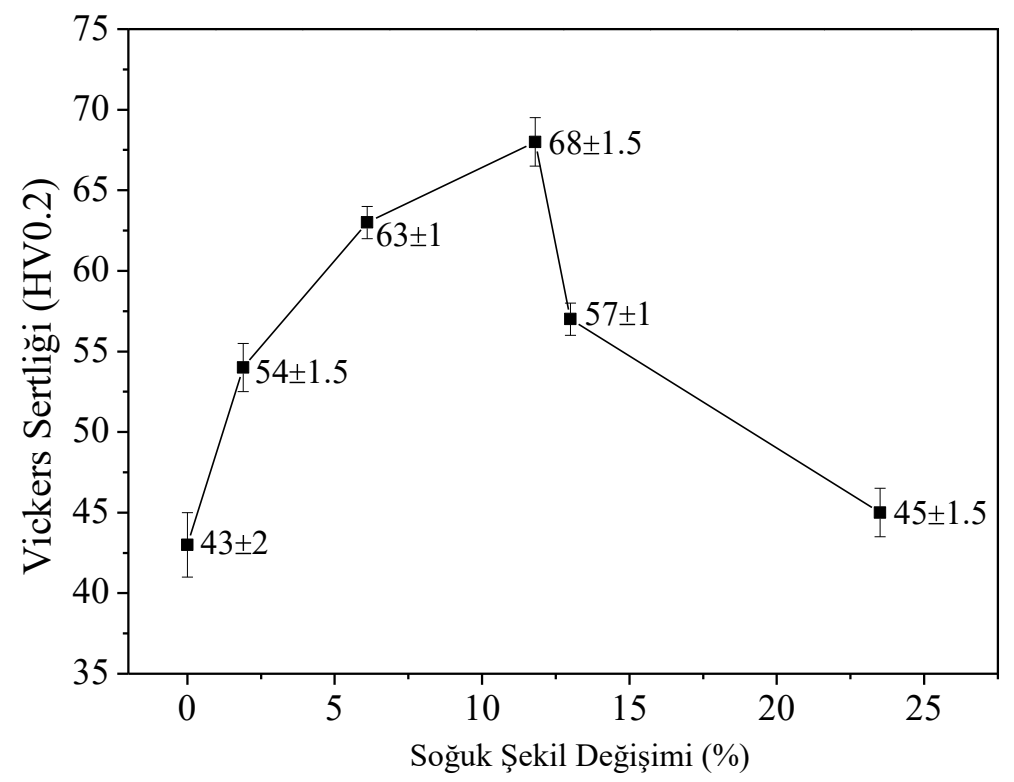

Şekil 6. $\mathrm{Al}-\% 2 \mathrm{Al}_{2} \mathrm{O}_{3}$ kompozit yapıda \% soğuk şekil değişimiyle (\%SŞD) Vickers sertliğindeki değişim.

Al-\% $2 \mathrm{Al}_{2} \mathrm{O}_{3}$ kompozitlerin soğuk deformasyon öncesi ve sonrası çekme test sonuçları Şekil 7'de verilmiştir. Kompozitin çekme dayanımı soğuk deformasyon işlemi öncesi (\%0 SŞD) $71 \mathrm{MPa}$ iken; soğuk deformasyon işlemi (\%11.8 SŞD) sonrası $92 \mathrm{MPa}$ 'a yükselmiştir. Özellikle sünek davranış gösteren metaller, soğuk deformasyon sonrası pekleşme etkisiyle daha yüksek sertliğe ve çekme dayanımına sahip olmaktadır. Bu durum, plastik deformasyon sebebiyle dislokasyon yoğunluğunun artmasından kaynaklanmaktadır. Artan deformasyon etkisiyle dislokasyonlar aras1 mesafe azalarak dislokasyon hareketi engellenmektedir. Böylece malzemenin mekanik özellikleri iyileşmektedir (Mansourinejad ve Mirzakhani, 2012; Hou vd., 2015). 

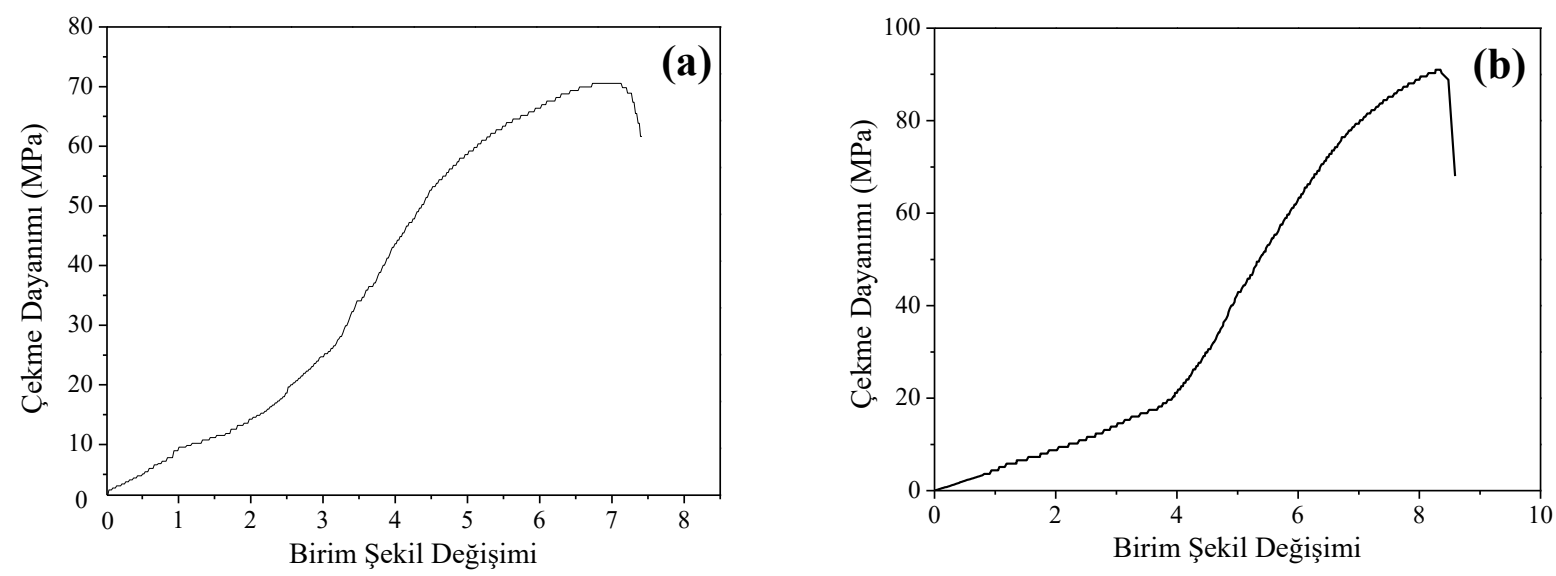

Şekil 7. Al- $\% 2 \mathrm{Al}_{2} \mathrm{O}_{3}$ kompozit yapıda \%soğuk şekil değişimiyle (\%SŞD) çekme dayanımındaki değişim: (a) $\% 0$ SŞD ve (b) \%11.8 SŞD.

\subsection{Alümina Katkısının ve Soğuk Şekil Değişiminin Kompozitlerin Mikroyapısına Etkisi}

Toz metalurjisi yöntemiyle üretilen saf alüminyum ve $\mathrm{Al}-\% 2 \mathrm{Al}_{2} \mathrm{O}_{3}$ kompozitlere ait $\mathrm{X}$ 1şını kırınımı (XRD) örgü desenleri Şekil 8'de verilmiştir. Şekilde saf Al'ye ait kırınım eğrisi incelendiğinde, en güçlü kırınım pikleri $2 \theta=38$,
45,65 ve $78^{\circ}$ de elde edilmiştir. $\mathrm{Al}-\% 2 \mathrm{Al}_{2} \mathrm{O}_{3}$ kompozite ait kırınım eğrisinde ise kırınım açılarının sırasılyla; $2 \theta=\sim 25^{\circ}, 35^{\circ}, 38^{\circ}, 43^{\circ}, 53^{\circ}$, $58^{\circ}, 61^{\circ}, 67^{\circ}, 68^{\circ}, 77^{\circ}$ olduğu belirlenmiştir. Ayrıca $\mathrm{Al}-\% 2 \mathrm{Al}_{2} \mathrm{O}_{3}$ kompozitin faz analizinde, yalnızca $\mathrm{Al}$ ve $\mathrm{Al}_{2} \mathrm{O}_{3}$ fazları yer almakta olup alüminyum karbür $\left(\mathrm{Al}_{4} \mathrm{C}_{3}\right)$ gibi istenmeyen ikincil fazlara rastlanmamıştır.

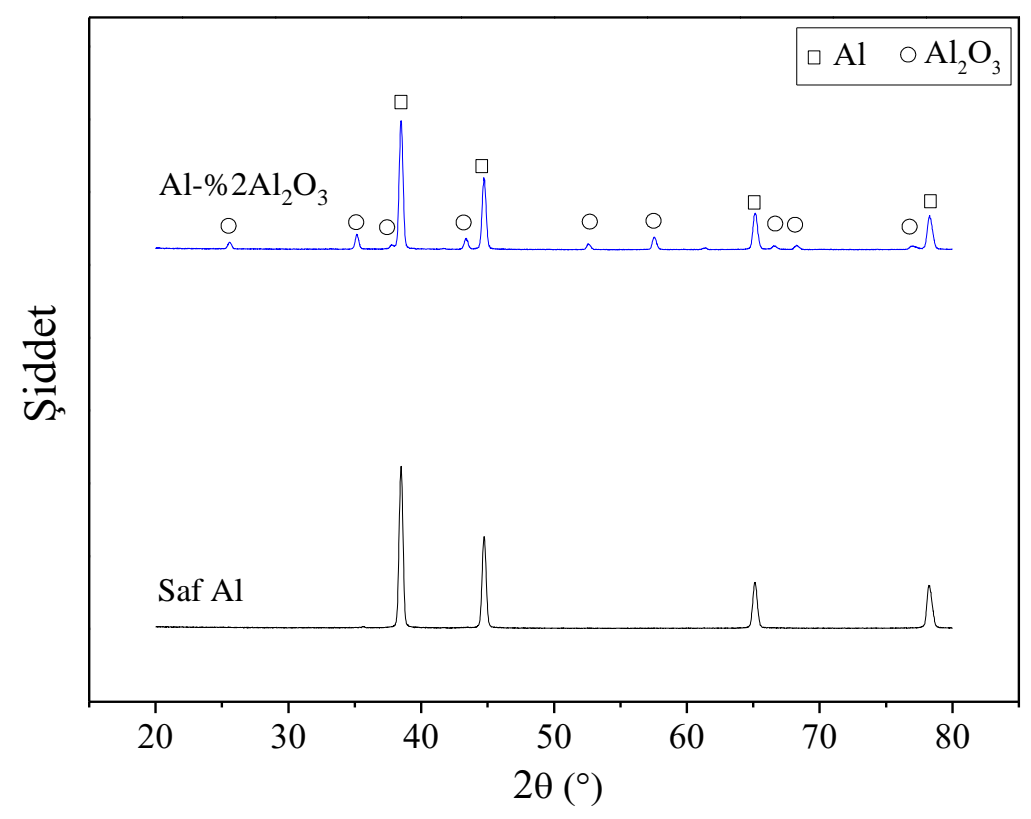

Şekil 8. Saf alüminyum ve Al- $\% 2 \mathrm{Al}_{2} \mathrm{O}_{3}$ kompozit yapıya ait $\mathrm{XRD}$ örgü desenleri.

Üretilen $\quad \mathrm{Al}-\% 1 \mathrm{Al}_{2} \mathrm{O}_{3}, \quad \mathrm{Al}-\% 1.5 \mathrm{Al}_{2} \mathrm{O}_{3}, \quad \mathrm{Al}-$ $\% 2 \mathrm{Al}_{2} \mathrm{O}_{3}$ ve $\mathrm{Al}-\% 2.5 \mathrm{Al}_{2} \mathrm{O}_{3}$ kompozitlerin taramalı elektron mikroskobu kırık yüzey içyapı görüntüleri Şekil 9'da verilmiştir. Kırık yüzey içyapı görüntülerinden, kompozit yapının oldukça yoğun olduğu, kırılmanın gevrek bir kırılma olduğu ve alüminyum taneciklerin boyun vererek iyi bir şekilde sinterlendiği belirlenmiştir. Al-
$\% 1 \mathrm{Al}_{2} \mathrm{O}_{3}, \quad \mathrm{Al}-\% 1.5 \mathrm{Al}_{2} \mathrm{O}_{3}$ ve $\mathrm{Al}-\% 2 \mathrm{Al}_{2} \mathrm{O}_{3}$ kompozit yapılarda alümina taneciklerin arayüzeyde yer alarak homojene yakın bir şekilde dağıldığ $1 ; \quad \mathrm{Al}-\% 2.5 \mathrm{Al}_{2} \mathrm{O}_{3}$ kompozit yapıda ise alümina taneciklerin topaklandığ 1 tespit edilmiştir. $\mathrm{Bu}$ topaklanmaların da $\mathrm{Al}-\% 2.5 \mathrm{Al}_{2} \mathrm{O}_{3}$ kompozitin mekanik özelliklerini olumsuz yönde etkilediği sonucuna varılmıştır. 

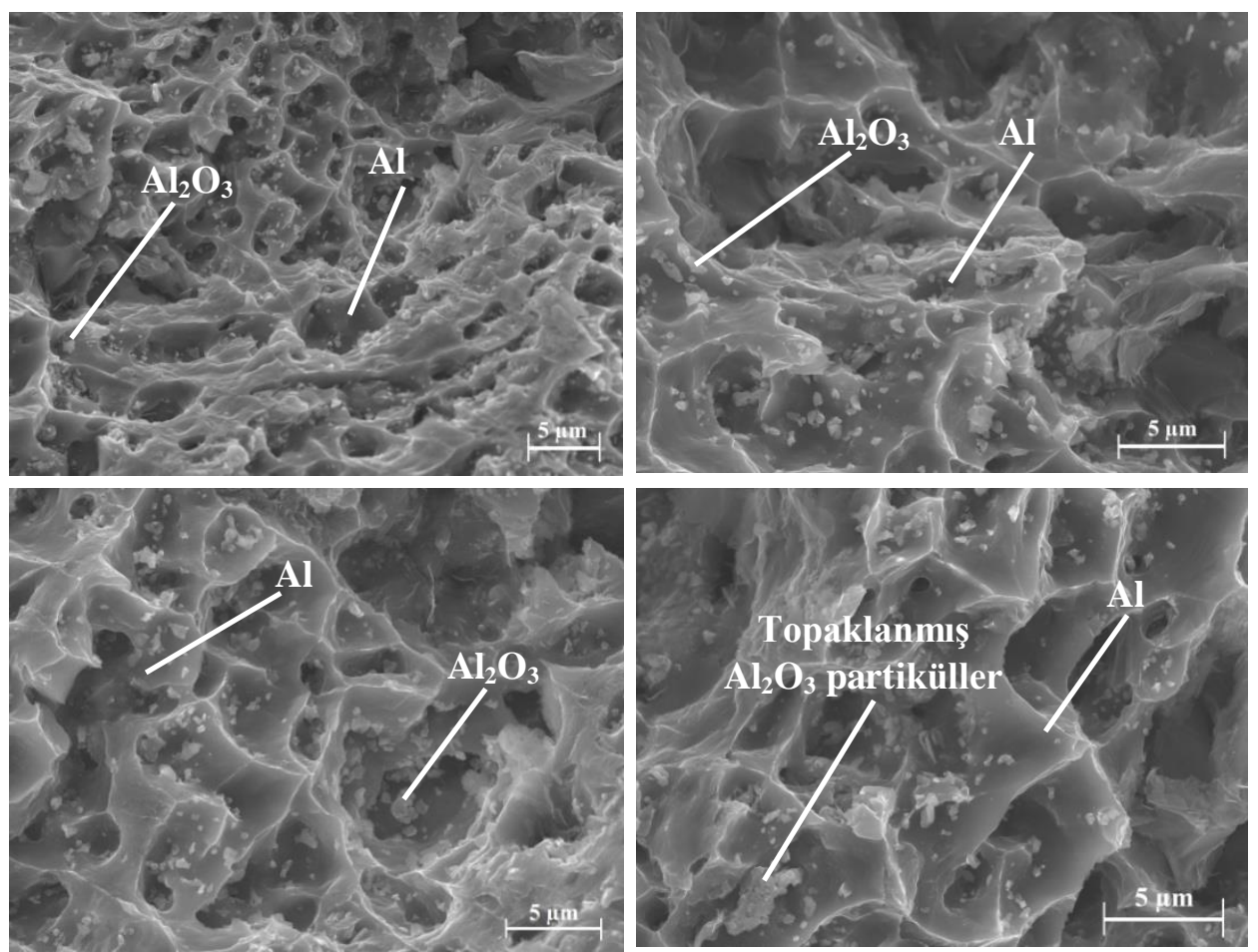

Şekil 9. Soğuk şekil değişimi öncesi üretilen kompozitlerin kırık yüzey içyap1 görüntüleri: (a) $\mathrm{Al}-\% 1 \mathrm{Al}_{2} \mathrm{O}_{3}$, (b) $\mathrm{Al}-\% 1.5 \mathrm{Al}_{2} \mathrm{O}_{3}$, (c) $\mathrm{Al}-\% 2 \mathrm{Al}_{2} \mathrm{O}_{3}$ ve (d) $\mathrm{Al}-\% 2.5 \mathrm{Al}_{2} \mathrm{O}_{3}$ kompozit yap1.

Toz metalurjisi yöntemiyle üretilen $\mathrm{Al}-\mathrm{Al}_{2} \mathrm{O}_{3}$ kompozitler basma gerilmeleri altında farklı yüzde soğuk şekil değişimine (\%SŞD) maruz bırakılmıştır. Soğuk şekil değişimine uğrayan kompozitlerin yüzeyi parlatılarak metal mikroskobuyla tanelerin görüntüleri elde edilmiştir (Şekil 10). \%11.8 SŞD’ye kadar Al tanelerinin farklı yönlerde yönlendiği ve daha yuvarlak olduğu tespit edilmiş̧tir. \%23.5 soğuk şekil değişimi oranında ise tanelerin soldan sağa doğru yöneldiği ve basma gerilmesi etkisiyle yukarıdan aşağıya doğru kesitin daraldığı belirlenmiştir. Sonuç olarak, aşırı soğuk şekil değişiminin (\%11.8 SŞD'den fazla) kompozitin mekanik özelliklerini olumsuz yönde etkilediği görülmüş̧ür.
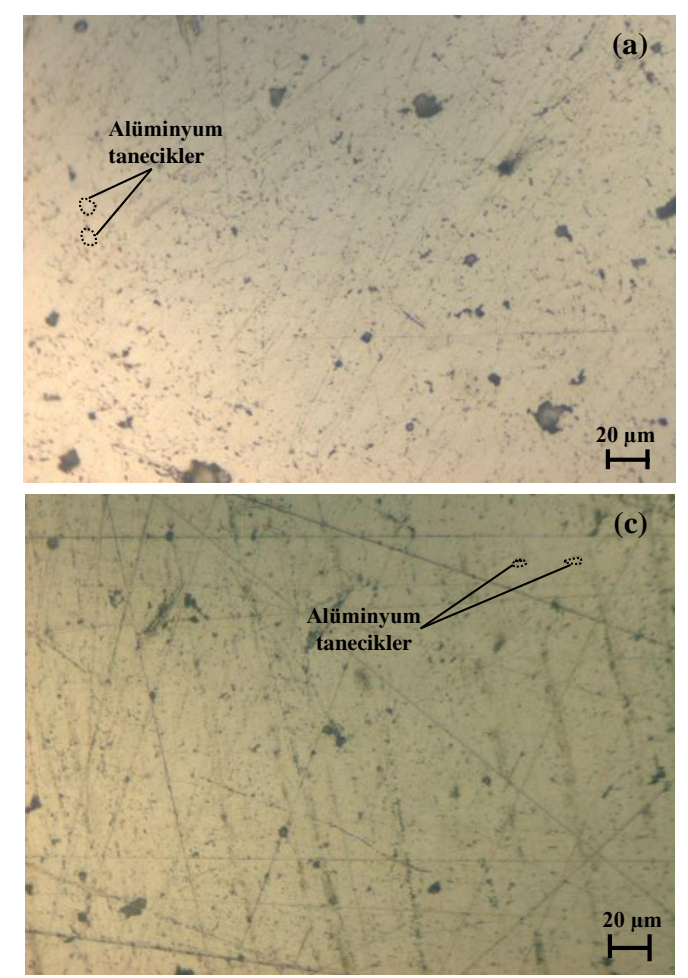

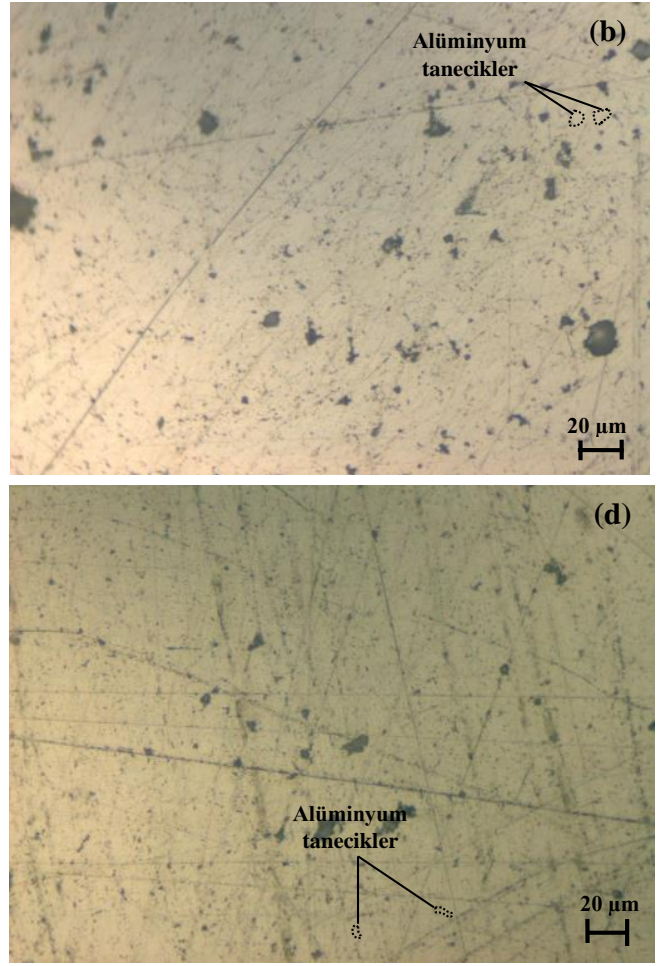

(d)

4 Şekil 10. Soğuk şekil değişimi öncesi ve sonras1 alüminyum tanelerin parlatılmış yüzey görüntüleri:
(a) $\% 0$, (b) $\% 6.1$,
(c) $\% 11.8$ ve (d)
$\% 23.5 \mathrm{SSSD}$ 


\section{Sonuçlar}

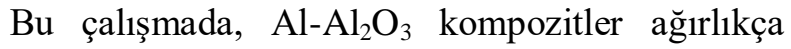
farklı alümina katk1 oranlarında $(\% 0,0.5,1,1.5$, 2 , 2.5) toz metalurjisi yöntemiyle başarılı bir şekilde üretilmiştir. Üretilen kompozilere uygulanan yoğunluk ve sertlik ölçümleri neticesinde; en iyi mekanik özelliklere sahip kompozit yap1 $\mathrm{Al}-\% 2 \mathrm{Al}_{2} \mathrm{O}_{3}$ olarak belirlenmiştir. Ağrılıkça \%2 alümina katkısından sonra kompozit yapıda alümina taneciklerin topaklanmas1 sebebiyle mekanik özellikler kötüleşmiştir. $\mathrm{Bu}$ sebeple $\mathrm{Al}-\% 2 \mathrm{Al}_{2} \mathrm{O}_{3}$ kompozit yap1 esas alınarak, farklı presleme basınçlarında $(50,100,150,200$, $250 \mathrm{MPa}$ ) soğuk şekil değişimi uygulanmıştır. En yüksek Vickers sertliği (68土1.5 HV) ve çekme dayanımı (92 MPa), \%11.8 oranında soğuk şekil değişimine maruz kalan $\mathrm{Al}-\% 2 \mathrm{Al}_{2} \mathrm{O}_{3}$ kompozit yapıda elde edilmiştir. \%11.8 oranındaki soğuk şekil değişimi etkisiyle kompozitin çekme dayanımı $+\% 30$ ve Vickers sertliği $+\% 53$ oranında artmıştır. Yürütülen mekanik testler ve mikroyap1 incelemeleri neticesinde; en uygun mikron altı boyutlu alümina katk1 oran1 $\% 2$ ve \%soğuk şekil değişimi oranı \%11.8 olarak belirlenmiştir.

\section{Kaynaklar}

Ashtiani, H.R.Z. ve Karami, P., 2015. Prediction of the microstructural variations of cold-worked pure aluminum during annealing process. Modeling and Numerical Simulation of Material Science, $5,1-14$.

Bastwros, M., Kim, G.Y., Zhang, C.Z.K., Wang, S. ve Tang, X., 2014. Effect of ball milling on graphene reinforced Al6061 composite fabricated by semi-solid sintering. Composites Part B-Engineering, 60, 111-118.

Burlat, M., Julien, D., Levesque, M., Bui-Quoc, T. ve Bernard, M., 2008. Effect of local cold working on the fatigue life of 7475-T7351 aluminium alloy hole specimens. Engineering Fracture Mechanics, 75, 2042-2061.

Callister, W.D. ve Rethwisch, D.G., 2014. Materials Science and Engineering, John Wiley\&Sons, Inc., USA, 215p.

Çapan, L., 2003. Metallere Plastik Şekil Verme, Çağlayan Kitabevi, İstanbul, 106s.

Ezatpour, H.R., Torabi Parizi, M., Sajjai, S.A., Ebrahimi, G.R. ve Chaichi, A., 2016. Microstructure, mechanical analysis and optimal selection of 7075 aluminum alloy based composite reinforced with alumina nanoparticles. Materials Chemistry and Physics, 178, 119-127.
German, R.M. 2007. Toz Metalurjisi ve Parçacıklı Malzeme İşlemleri (Çev. Türk Toz Metalurjisi Derneği), Türk Toz Metalurjisi Derneği Yayınları, ISBN: 975-924-632-5, Ankara, 574s.

Gökmeşe, H. ve Bostan, B., 2013. AA 2014 alaşımında presleme ve sinterlemenin gözenek morfolojisi ve mikroyapısal özelliklere etkileri. Gazi Üniversitesi Fen Bilimleri Dergisi Part:C, 1, 1, $1-8$.

Gürbüz, M., Şenel, M.C., Koç, E., 2018a. The effect of sintering temperature, time and graphene addition on the mechanical properties and microstructure of aluminum composites. Journal of Composite Materials, 52, 4, 553-563.

Gürbüz, M., 2018b. Atık içecek kutularından üretilmiş alüminyumun mekanik özelliklerine soğuk işlemin. Etkisi. Dokuz Eylül Üniversitesi Mühendislik Fakültesi Fen ve Mühendislik Dergisi, 20, 58, 28-35.

Hou, M.J.P., Wang, Q., Yang, H.J., Wu, X.M., Li, C.H., Li, X.W. ve Zhang, Z.F., 2015. Microstructure evolution and strengthening mechanisms of cold-drawn commercially pure aluminum wire. Materials Science\& Engineering A, 639, 103-106.

Kaczmar, J.W., Pietrzak, K. ve Wlonsinski, W., 2000. The production and application of metal matrix composite materials. Journal of Materials Processing Technology, 106, 58-67.

Kok, M., 2005. Production and mechanical properties of $\mathrm{Al}_{2} \mathrm{O}_{3}$ particle-reinforced 2024 aluminium alloy composites. Journal of Materials Processing Technology, 161, 381-387.

Kurşun, T., 2011. Alüminyum esaslı $\mathrm{SiC}$ takviyeli metal matrisli kompozitlerin birleştirilmesinde $\mathrm{Al}_{4} \mathrm{C}_{3}$ oluşumunun önlenmesi ve sinerjik kontrollü darbeli MIG (GMAW-P) kaynak yöntemi. Selçuk Üniversitesi Teknik Bilimler Meslek Yüksekokulu Teknik-Online Dergi, 10, 1, 86-98.

Lianggang, G,, Shuang, Y., He, Y. ve Jun, Z., 2015. Processing map of as-cast 7075 aluminum alloy for hot working. Chinese Journal of Aeronautics, 28, 6, 1774-1783.

Mansourinejad, M. ve Mirzakhani, B., 2012. Influence of sequence of cold working and aging treatment on mechanical behaviour of 6061 aluminum alloy. Transactions of Nonferrous Metals Society of China, 22, 2072-2079.

Martinez, V.P, Torres, J.T. ve Valdes, A.F., 2017. Recycling of aluminum beverage cans for metallic foams manufacturing. Journal of Porous Materials. 24, 707-712. 
Öztop, B. ve Gürbüz, M., 2018. Investigation of properties of composites produced from waste aluminum with $\mathrm{Si}_{3} \mathrm{~N}_{4}$ reinforcement. Technological Applied Sciences, 13, 1, 57-66.

Rahimian, M., Parvin, N ve Ehsani, N., 2011. The effect of production parameters on microstructure and wear resistance of powder metallurgy $\mathrm{Al}-\mathrm{Al}_{2} \mathrm{O}_{3}$ composite. Materials and Design, 32, 1031-1038.

Sajjadi, S.A., Ezatpour, H.R. ve Beygi, H., 2011. Microstructure and mechanical properties of $\mathrm{Al}-\mathrm{Al}_{2} \mathrm{O}_{3}$ micro and nano composites fabricated by stir casting. Materials Science and Engineering A, 528, 8765-8771.

Sharma, P., Sharma, S. ve Khanduja, D. 2015. Production and some properties of $\mathrm{Si}_{3} \mathrm{~N}_{4}$ reinforced aluminium alloy composites. Journal of Asian Ceramic Societies, 3, 352-359.

Srivastava, N. ve Chaudhari, G.P., 2018. Microstructural evolution and mechanical behavior of ultrasonically synthesized Al6061nano alumina composites. Materials Science\&Engineering A, 724, 199-207.
Şahin, İ., 2014. Alüminyum matrisli kompozit malzemelerin matkap ile delinmesi konusunda yapılan çalışmaların incelenmesi. Mühendis ve Makina Dergisi, 55, 649, 9-16.

Şahin, Y., 2006. Kompozit Malzemelere Giriş, Seçkin Yayınevi, Ankara, 436s.

Şenel, M.C., Gürbüz, M. ve Koç, E., 2015. Grafen takviyeli alüminyum matrisli yeni nesil kompozitler. Mühendis ve Makina Dergisi, 56, 669, 36-47.

Şenel, M.C, Gürbüz, M. ve Koç, E. 2017. Grafen takviyeli alüminyum esaslı kompozitlerin üretimi ve karakterizasyonu. Pamukkale Üniversitesi Mühendislik Bilimleri Dergisi, 23, 8, 974-978.

Şenel, M.C., Gürbüz, M. ve Koç, E., 2018. The Fabrication and characterization of synergistic Al-SiC-GNPs hybrid composites. Composites Part B-Engineering, 154, 1-9.

Torralba, J.M., Costa, C.E. ve Velasco, F., 2003. P/M aluminum matrix composites: an overview. Journal of Materials Processing Technology, 133, 1, 203-206. 